\title{
Factors that Affect the Adherence to ADHD Medications during a Treatment Continuation Period in Children and Adolescents: A Nationwide Retrospective Cohort Study Using Korean Health Insurance Data from 2007 to 2011
}

\author{
Soo-Young Bhang ${ }^{1}$, Young Sook Kwack², Yoo-Sook Joung ${ }^{3}$, Soyoung Irene Lee ${ }^{4}$, Bongseog Kim ${ }^{5}$, \\ Seok Han Sohn ${ }^{6}$, Un-Sun Chung ${ }^{7}$, Jaewon Yang ${ }^{8}$, Minha Hong ${ }^{9}$, Geon Ho Bahn ${ }^{10}$, \\ Hyung-yun Choi ${ }^{11}$, In Hwan $\mathrm{Oh}^{12}$, Yeon Jung Lee ${ }^{13}$, and Jun-Won Hwang ${ }^{14 \bowtie}$ \\ 'Department of Psychiatry, Eulji University School of Medicine, Eulji University Eulji Hospital, Seoul, Republic of Korea \\ ${ }^{2}$ Department of Psychiatry, Jeju National University College of Medicine, Jeju, Republic of Korea \\ ${ }^{3}$ Department of Psychiatry, Sungkyunkwan University School of Medicine, Seoul, Republic of Korea \\ ${ }^{4}$ Department of Psychiatry, Soonchunhyang University College of Medicine, Bucheon Hospital, Bucheon, Republic of Korea \\ ${ }^{5}$ Department of Psychiatry, Sanggyepaik Hospital School of Medicine, Inje University, Seoul, Republic of Korea \\ ${ }^{6}$ Yonsei Clinic of Psychiatry, Seoul, Republic of Korea \\ ${ }^{7}$ Department of Psychiatry, Kyungpook National University School of Medicine, Daegu, Republic of Korea \\ ${ }^{8}$ Stress Clinic, Korea Advanced Institute of Science and Technology (KAIST) Clinic, Daejeon, Republic of Korea \\ ${ }^{9}$ Department of Psychiatry, Myongji General Hospital, Goyang, Republic of Korea \\ ${ }^{10}$ Department of Psychiatry, Kyung Hee University School of Medicine, Seoul, Republic of Korea \\ ${ }^{11}$ Korea Centers for Disease Control and Prevention, Cheongju, Republic of Korea \\ ${ }^{12}$ Department of Preventive Medicine, Kyung Hee University School of Medicine, Seoul, Republic of Korea \\ ${ }^{13}$ Department of Psychiatry, Soonchunhyang University College of Medicine, Seoul Hospital, Seoul, Republic of Korea \\ ${ }^{14}$ Department of Psychiatry, Kangwon National University School of Medicine, Chuncheon, Republic of Korea
}

Objective Several factors, such as male gender, older age, type of insurance, comorbid conditions, and medication type, have been associated with attention-deficit/hyperactivity disorder (ADHD) medication adherence rates, but the results have been inconsistent. We analyzed data to answer several questions: 1) How old were patients who first refilled their treatment medications used primarily for $\mathrm{ADHD}$, regardless of the medication type? 2) What socio-demographic factors are associated with medication adherence? 3) What medical conditions, such as medication type and comorbid diagnosis, influence adherence?

Methods We analyzed National Health Insurance data, which comprised continuously enrolled Korean National Medical Insurance children (6-18 years) with at least 2 ADHD prescription claims (January 2008-December 2011). The persistence of use regarding the days of continuous therapy without a 30-day gap were measured continuously and dichotomously. Adherence, using a medication possession ratio (MPR), was measured dichotomously ( $80 \%$ cut-off).

Results The cumulative incidence of index cases that initiated medication refills for ADHD treatment during the 4 year period was $0.85 \%$. The patients who exhibited a MPR greater than 80 comprised approximately $66 \%$. The medication type, high school age groups, physician speciality, treatment at a private clinic, and comorbid conditions were associated with medication adherence during continuous treatment using a multivariate analysis.

Conclusion A better understanding of ADHD treatment patterns may lead to initiatives targeted at the improvement of treatment adherence and persistence. Other factors, including the severity, family history, costs, type of comorbidities, and switching patterns, will be analyzed in future studies.

Psychiatry Investig 2017;14(2):158-165

Key Words ADHD, Compliance, Adherence, Stimulants, Atomoxetine, Cohort.

Received: February 12, 2016 Revised: February 24, 2016 Accepted: March 17, 2016 Available online: November 2, 2016

$\triangle$ Correspondence: Jun-Won Hwang, MD

Department of Psychiatry, Kangwon National University School of Medicine, 156 Baengnyeong-ro, Chuncheon 24289, Republic of Korea Tel: +82-33-258-9410, Fax: +82-33-254-1376, E-mail: huangjw@daum.net

@ This is an Open Access article distributed under the terms of the Creative Commons Attribution Non-Commercial License (http://creativecommons.org/licenses/by-nc/4.0) which permits unrestricted non-commercial use, distribution, and reproduction in any medium, provided the original work is properly cited. 


\section{INTRODUCTION}

Attention-deficit/hyperactivity disorder (ADHD) is the most common childhood disorder in psychiatric outpatient clinics, and it affects approximately $5.3 \%$ of the school aged population. ${ }^{1}$ ADHD has been regarded as a chronic condition that may continue through adulthood. Children and adolescents with ADHD have increased risks for school dropout and contact with the law, earlier substance use associated with conduct problems, mood and anxiety disorders, dangerous driving, problem gambling, and eating disorders. ${ }^{2-6}$

Continued medication treatment leads to the improvement of academic outcomes and a reduction of psychiatric comorbidities and adverse behavior problems, including smoking and substance use; ${ }^{7-10}$ thus, earlier detection and better adherence to prescribed medication are significant factors throughout the long-term treatment of children and adolescents with ADHD. Unfortunately, it has been reported that suboptimal treatment and poor medication adherence are common and lead to less than optimal outcomes in children and adolescents with ADHD after 12 months of treatment. ${ }^{11-13}$

In their recent review, Charach and Fernandez listed several factors associated with poor ADHD medication adherence as follows: 1) For the parent/family factors, older parents, increased parent-child conflict, the belief that symptoms are not a disorder, distrust of the medical system, stigma, burden of the medication regimen, and concerns regarding medication safety decreased adherence. 2) For the child factors, older aged child at diagnosis, family history of ADHD, severe behavior problems at home, and an unwilling child decreased adherence. 3) For the adolescent factors, negative attitudes toward medication, stigma, concerns regarding treatment dependence, and experience of social withdrawal decreased adherence. 4) For the Healthcare system/professional factors, the cost of medication and lack of providers in the community decreased adherence. 5) For the final factor Medication, medication ineffectiveness, adverse effects, multiple daily doses, and difficulties adjusting the dose regimen decreased adherence. $^{14}$

There have been reports using claims data from selected populations to evaluate the adherence to ADHD medication in several countries. However, these studies were limited to selected populations in Managed Care or Medicaid in the US, ${ }^{13,15}$ beneficiaries of the Social Assistance program (Quebec provincial health plan database) in Canada, ${ }^{16}$ and the Health Improvement Network (THIN) without any direct coding by specialist database in the UK primary care. ${ }^{17} \mathrm{Re}-$ ports from Demark used the Danish Registry of Medicinal Product Statistics, which only contained medication records without diagnostic information. ${ }^{18,19}$
In contrast, the use of claims data has unique benefits, especially in South Korea because all South Koreans should use the National Health Insurance or Medicaid service under the National Health Insurance Law established in $1989 .{ }^{20}$ According to data from 2013, approximately 49,970,000 individuals (97.2\%) have the National Health Insurance and 1,461,000 individuals (2.8\%) have Medicaid..$^{21}$ In the Health Insurance Review and Assessment (HIRA) database, nearly all medical claim records from the National Health Insurance (NHI) and Medicaid in Korea exist since 2002. ${ }^{22}$ In the database, the International Classification of Diseases, 10th Revision (ICD-10) has been used to code specific diagnoses and related signs and symptoms. Therefore, the national claims data from the HIRA database have characteristics of the birth cohort of all individuals in Korea. These features also enable the assessment of a nationwide source of information regarding the use of health care resources during ADHD treatment.

In our recent report regarding the ADHD prevalence in Korea, ${ }^{23}$ the average annual diagnostic incidence of ADHD in the $6-18$ years of age population was $0.357 \%(29,310.5 /$ $8,218,252)$, and the incidence of medication use for ADHD was $0.248 \%(20,340.3 / 8,218,252)$ in 2008-2011. Among newly diagnosed $\mathrm{ADHD}$ patients, the osmotic-controlled release oral delivery system (OROS) methylphenidate was the most commonly used first prescribed medication, and depression was the most common comorbid psychiatric diagnosis using the ICD-10. In light of the need to improve adherence to ADHD medications, we attempted to address several questions in this study. 1) How old were the patients who first refilled their treatment medications, regardless of the medication type, used primarily for ADHD? 2) What socio-demographic factors (e.g., age, gender, insurance type, place of living, hospital level, and specialist type) were associated with medication adherence? 3) Could medical conditions, such as medication types and comorbid diagnosis, influence adherence?

\section{METHODS}

\section{Data source and study population}

This retrospective analysis used data from the HIRA claims database from January 1, 2007 to December 31, 2011. We recently reported the sampling method and the characteristics of the HIRA data. ${ }^{23}$ The participants comprised children and adolescents between 6 and 18 years of age who presented an inpatient or outpatient medical claim that contained a code for the diagnosis of ADHD (ICD-10 code F90.0) between January 1, 2008 and December 31, 2011, who had at least one medication refill of an ADHD medication and no medication use during the 360 days that preceded the claim. Information regarding the socio-demographic factors, such as age, sex, and 
type of insurance, and medical factors, including hospital level and clinician specialty, were obtained from the HIRA database. This study was approved by the Institutional Review Board of Eulji University, Eulji General Hospital, Seoul, South Korea (IRB No. 2015-01-012).

\section{Study variables}

\section{Medication categories}

We categorized the ADHD medications available in South Korea from 2008 to 2011 into immediate-release methylphenidate (IR-MPH), extended-release (ER) MPH, and osmoticcontrolled release oral delivery system (OROS) MPH, atomoxetine, and a combination of two or more medications. At this time, immediate-release methylphenidate $\left(\mathrm{Penid}^{\mathrm{TM}}\right)$, extended-release methylphenidate (Metadate $\mathrm{CD}^{\mathrm{TM}}$ ), osmoticcontrolled release methylphenidate (Concerta ${ }^{\mathrm{TM}}$ ), and the non-stimulant were indicated as a treatment for patients who initiated their treatment with this medication at 6-18 years of age; however, atomoxetine was only covered when specific comorbid conditions, such as severe anxiety and Tourette syndrome, were also present. The combination of these medications was typically not covered by Korean national insurance.

\section{Patient persistence and adherence}

There are two indicators of medication compliance. In this study, persistence was defined as the number of days of continuous therapy (without a 30 day gap period) during the postindex period (from the index date to the last date of medication prescription). Medication adherence was calculated using the medication possession ratio (MPR). The MPR reflects the proportion of days that patients were in possession of their prescribed medication, which thus indicates adherence. In our study, the MPR was measured by summing the day supply and dividing by the treatment period days (e.g., the last date of medication prescription-index date); the conventional $80 \%$ cut-off was used.

\section{Covariates}

Age was divided into five age groups: 6, 7-9, 10-12, 13-15, and 16-18 years old, which corresponded to the structure of the Korean school system (preschool, upper and lower grades of elementary school, middle school and high school, respectively). The insurance types were classified into two categories: national health insurance and Medical aid. The clinician specialties were categorized as psychiatry, pediatrics and others. The hospital level was stratified into two groups: general hospital and private clinic. For the comorbidity analysis, we examined all psychiatric diagnoses in the newly diagnosed patients with ADHD. ${ }^{23}$

\section{Statistical analysis}

Descriptive statistics (means and frequencies) were used to characterize the medication use, adherence, and persistence, as well as the clinical and demographic variables. To assess the factors associated with adherence and persistence, a multivariate logistic regression analysis was employed. SAS 9.3 (SAS Institute, Inc., Cary, NC, USA) was used to analyze the data. An a priori significance level of $\mathrm{p}<0.05$ was used throughout all statistical analyses.

\section{RESULTS}

\section{Participants}

Our study sample of children and adolescents with ADHD and medication claims 2 times or more was 69,631, and the mean population of 6-18 year olds between 2008 to 2011 in South Korea was 8,218,252.23 Therefore, the cumulative incidence of index cases that initiated a medication refill for $\mathrm{ADHD}$ treatment during the 4 year period was $0.9 \%$. The study sample $[\mathrm{n}=69,631$, mean age 10.3 years $(\mathrm{SD}=3.24)]$ largely consisted of boys ( $\mathrm{n}=53,907,77.4 \%)$, patients who had national health insurance $(\mathrm{n}=64,968,93.3 \%)$, lived in an urban area $(n=42,572,64.1 \%)$, and were treated in a private clinic $(\mathrm{n}=50,918,73.1 \%)$ by psychiatrists $(66,937,96.1 \%)$. In our sample of children and adolescents with a diagnosis of ADHD, 24,754 subjects (35.6\%) were 7-9 years old, 16,639 subjects (23.9\%) were 10-12 years old, 14,704 subjects (21.1\%) were 13-15 years old, 8,252 subjects (11.9\%) were 6 years old, and 5,282 subjects (7.6\%) were $16-18$ years old. The first prescribed medication was mainly OROS-MPH $(\mathrm{n}=25,457$, $36.6 \%)$, followed by ER-MPH ( $\mathrm{n}=23,686,34.0 \%)$, IR-MPH $(\mathrm{n}=13,721,19.7 \%)$, and atomoxetine $(4,193,6.0 \%)$, respectively. The combination of any medication was identified in 2,574 subjects $(3.7 \%)$ (Table 1 ).

A total of 5,894 children and adolescents, which included 4,614 boys (8.6\%) and 1,250 girls (8.0\%), exhibited a more than 30 day GAP (GAP30) during their individual follow-up period. The mean days before the GAP30 was 216.9 (SD= 249.1, median=124.0), which was longer in the boys (221.7, $\mathrm{SD}=127)$ compared with the girls $(199.0, \mathrm{SD}=105.5)(\mathrm{p}<0.01)$. Among the age groups, the highest mean days before the GAP30 was identified for the 6 years of age group (261.8 \pm 281.3 in the boys, $241.8 \pm 127.5$ in the girls), followed by the $7-9,10-12,13-15$, and $16-18$ years of age groups (238.8 \pm $256.9,208.8 \pm 232.2,221.1 \pm 244.7$, and $192.9 \pm 246.8$, respectively, in the boys; $172.3 \pm 224.5,187.6 \pm 250.2,126.1 \pm 147.1$, and 139.3 \pm 154.6 , respectively, in the girls) (Table 2).

Comparisons of the persistence and adherence between the boys and girls are presented in Table 3 and Figure 1. The mean proportion of medication persistence without a 30 day 
gap was $66.4 \%$ in the boys and $66.8 \%$ in the girls. The mean days before the 30 day gap were 221.7 ( $S D=251.1$, median=127.0, interquartile 35-324) days in the boys and 199.07
$(\mathrm{SD}=241.0$, median=105.5, interquartile 29-280) days in the girls. Approximately $66.39 \%$ of the boys and $66.84 \%$ of the girls in this sample achieved MPRs of $80 \%$.

Table 1. Demographic characteristics of the participants

\begin{tabular}{|c|c|c|c|c|c|c|}
\hline & \multicolumn{2}{|c|}{ Boys } & \multicolumn{2}{|c|}{ Girls } & \multicolumn{2}{|c|}{ Total } \\
\hline & $\mathrm{N}$ & $\%$ & $\mathrm{~N}$ & $\%$ & $\mathrm{~N}$ & $\%$ \\
\hline Age (yr) mean (SD) & 10.13163 & 3.18126 & 10.98448 & 3.36541 & 10.32422 & 3.2434 \\
\hline Median (range) & 10 & $7-13$ & 11 & $8-14$ & 10 & $7-13$ \\
\hline 6 & 6,848 & 12.7 & 1,404 & 8.93 & 8,252 & 11.85 \\
\hline $7-9$ & 19,923 & 36.96 & 4,831 & 30.72 & 24,754 & 35.55 \\
\hline $10-12$ & 12,946 & 24.02 & 3,693 & 23.49 & 16,639 & 23.9 \\
\hline $13-15$ & 10,682 & 19.82 & 4,022 & 25.58 & 14,704 & 21.12 \\
\hline $16-18$ & 3,508 & 6.51 & 1,774 & 11.28 & 5,282 & 7.59 \\
\hline \multicolumn{7}{|l|}{ Health insurance } \\
\hline National health insurance & 50,536 & 93.75 & 14,432 & 91.78 & 64,968 & 93.3 \\
\hline Medical aid & 3,371 & 6.25 & 1,292 & 8.22 & 4,663 & 6.7 \\
\hline \multicolumn{7}{|l|}{ Hospital level } \\
\hline General & 15,038 & 27.9 & 3,675 & 23.37 & 18,713 & 26.87 \\
\hline Private & 38,869 & 72.1 & 12,049 & 76.63 & 50,918 & 73.13 \\
\hline \multicolumn{7}{|l|}{ Region } \\
\hline Urban & 32,576 & 60.43 & 9,996 & 63.57 & 42,572 & 64.14 \\
\hline Rural & 21,331 & 39.57 & 5,728 & 36.43 & 27,059 & 38.86 \\
\hline \multicolumn{7}{|l|}{ Clinician specialty } \\
\hline Psychiatrist & 51,863 & 96.21 & 15,074 & 95.87 & 66,937 & 96.13 \\
\hline Pediatrician & 1,243 & 2.31 & 354 & 2.25 & 1,597 & 2.29 \\
\hline Others & 801 & 1.49 & 296 & 1.88 & 1,097 & 1.58 \\
\hline Any psychiatric comorbidity* & 49,058 & 91.00 & 14,248 & 90.61 & 63,306 & 90.91 \\
\hline \multicolumn{7}{|l|}{ Medication received } \\
\hline IR-MPH & 10,367 & 19.23 & 3,354 & 21.33 & 13,721 & 19.71 \\
\hline ER-MPH & 18,307 & 33.96 & 5,379 & 34.21 & 23,686 & 34.02 \\
\hline OROS-MPH & 19,837 & 36.8 & 5,620 & 35.74 & 25,457 & 36.56 \\
\hline Atomoxetine & 3,359 & 6.23 & 834 & 5.3 & 4,193 & 6.02 \\
\hline All combination & 2,037 & 3.76 & 537 & 3.41 & 2,574 & 3.69 \\
\hline
\end{tabular}

*multiple DSM diagnostic conditions for each children were counted respectively. IR-MPH: immediate release methylphenidate, ER-MPH: extended release methylphenidate, OROS-MPH: osmotic-controlled release oral delivery system methylphenidate, SD: standard deviation

Table 2. Days before a 30 day gap during the observation period

\begin{tabular}{|c|c|c|c|c|c|c|c|}
\hline \multirow{2}{*}{\multicolumn{2}{|c|}{30 day gap }} & \multicolumn{5}{|c|}{ Age group (yr) } & \multirow{3}{*}{$\begin{array}{c}\text { Total } \\
221.74\end{array}$} \\
\hline & & \multirow{2}{*}{$\frac{6}{261.80}$} & \multirow{2}{*}{$\frac{7-9}{238.88}$} & \multirow{2}{*}{$\frac{10-12}{221.06}$} & \multirow{2}{*}{$\begin{array}{c}13-15 \\
172.26\end{array}$} & \multirow{2}{*}{$\frac{16-18}{126.13}$} & \\
\hline Boys & Mean & & & & & & \\
\hline & (SD) & $(281.27)$ & $(256.88)$ & $(244.71)$ & $(224.51)$ & $(147.06)$ & (251.07) \\
\hline & Median & 164.5 & 144.5 & 133 & 87 & 64.5 & 127 \\
\hline & (IQR) & $(43-391)$ & $(44-359)$ & $(36-312)$ & $(25-210)$ & $(20-192)$ & $(35-324)$ \\
\hline \multirow[t]{4}{*}{ Girls } & Men & 241.79 & 208.81 & 192.87 & 187.61 & 139.25 & 199.07 \\
\hline & (SD) & $(272.17)$ & $(232.16)$ & $(246.75)$ & $(250.16)$ & (154.54) & (241.03) \\
\hline & Median & 127.5 & 120.5 & 88 & 94.5 & 67 & 105.5 \\
\hline & (IQR) & $(35-337)$ & $(41-306)$ & $(26-273)$ & $(20.5-249.5)$ & $(28-203)$ & $(29-280)$ \\
\hline
\end{tabular}

IQR: interquartile range, SD: standard deviation 
Table 3. Comparison of medication possession ratios among the patient age groups

\begin{tabular}{clcccccc}
\hline & \multicolumn{5}{c}{ Age group (yr) } \\
\cline { 3 - 7 } & & 6 & $7-9$ & $10-12$ & $13-15$ & $16-18$ & Total \\
\hline No of & Boys, N & 6,848 & 19,923 & 12,946 & 10,682 & 3,508 & 53,907 \\
participants & Girls, N & 1,404 & 4,831 & 3,693 & 4,022 & 1,774 & 15,724 \\
MPR (80) & Boys, N (\%) & $4,664(68.11)$ & $13,397(67.24)$ & $8,500(65.66)$ & $6,865(64.27)$ & $2,363(67.36)$ & $35,789(66.39)$ \\
& Girls, N (\%) & $957(68.16)$ & $3,280(67.89)$ & $2,478(67.10)$ & $2,579(64.12)$ & $1,216(68.55)$ & $10,510(66.84)$ \\
\hline
\end{tabular}

MPR: medication possession ratio

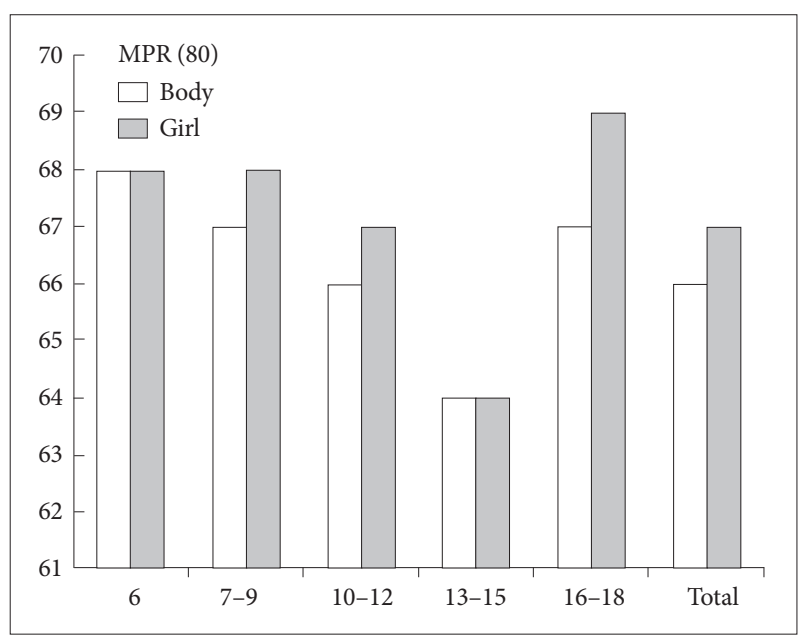

Figure 1. Comparison of medication possession ratios among the patient age groups. Comparisons of the persistence and adherence between the boys and girls are presented. The mean proportion of medication persistence without a 30 day gap was $66.4 \%$ in the boys and $66.8 \%$ in the girls.

The results from the multivariate logistic analysis of the Persistence (30 day gap) and Adherence (MPR 80\%) after adjustment for age and medication type are presented in Table 4. In the multivariate logistic analysis of persistence (30 day gap), having national medical insurance lowers the odds by 0.784 compared with Medicaid, and treatment in an urban area or private clinic increases the odds by 1.07 or 0.651 , respectively. In addition, psychiatric comorbidity increases the odds by 1.204 compared with no psychiatric comorbidity. Regarding the MPR (80\%), treatment by a specialist increased the odds approximately 1.4 times. Treatment at a private clinic increased the odds by 1.47 , and psychiatric comorbidity increased the odds by 1.301 .

We investigated the effects of the age cohort, gender, insurance type, professions who prescribe the medication, regions, clinic types, presence of comorbidities, and medication types on the adherence to ADHD medication treatment during the treatment period. The medication type [atomoxetine $(\mathrm{OR}=1.8$, $\mathrm{CI}=1.6-2.0)>$ ER-MPH $(\mathrm{OR}=1.3, \mathrm{CI}=1.2-1.4)$, OROS-MPH $(\mathrm{OR}=1.3, \mathrm{CI}=1.2-1.4)>\mathrm{IR}-\mathrm{MPH}(\mathrm{OR}=0.8, \mathrm{CI}=0.8-0.9)$, reference $=$ all combinations], age $10-15$ [age $10-12(\mathrm{OR}=0.9$, $\mathrm{CI}=0.8-1.0)$ and age $13-15(\mathrm{OR}=0.8, \mathrm{CI}=0.8-0.9)$, reference $=$ age 16-18], clinician specialty [psychiatrist $(\mathrm{OR}=1.4, \mathrm{CI}=1.1-$
Table 4. Multiple regression analysis of the MPR $(80 \%)$

\begin{tabular}{|c|c|c|}
\hline & \multicolumn{2}{|c|}{ MPR 80\% } \\
\hline & OR & $95 \% \mathrm{CI}$ \\
\hline \multicolumn{3}{|l|}{ Age (yr) } \\
\hline 6 & 1.073 & $0.994-1.158$ \\
\hline $7-9$ & 0.988 & $0.925-1.054$ \\
\hline $10-12$ & 0.909 & $0.85-0.972$ \\
\hline $13-15$ & 0.844 & $0.789-0.903$ \\
\hline $16-18$ & Ref & Ref \\
\hline \multicolumn{3}{|l|}{ Sex } \\
\hline Ref=boy & 1.03 & $0.991-1.07$ \\
\hline \multicolumn{3}{|l|}{ Insurance } \\
\hline Ref $=$ medical aid & 1.05 & $0.985-1.119$ \\
\hline \multicolumn{3}{|l|}{ Region } \\
\hline Ref=urban & 0.97 & $1.001-0.94$ \\
\hline \multicolumn{3}{|l|}{ Specialty } \\
\hline Psychiatrist & 1.356 & $1.198-1.534$ \\
\hline Pediatrician & 1.451 & $1.233-1.708$ \\
\hline Others & Ref & Ref \\
\hline \multicolumn{3}{|l|}{ Hospital level } \\
\hline General & Ref & Ref \\
\hline Private & 1.57 & $1.514-1.629$ \\
\hline \multicolumn{3}{|l|}{ Comorbidity } \\
\hline Comorbidity=yes (ref) & 1.301 & $1.259-1.346$ \\
\hline \multicolumn{3}{|l|}{ Medication type } \\
\hline IR-MPH & 0.843 & $0.772-0.921$ \\
\hline ER-MPH & 1.275 & $1.171-1.389$ \\
\hline OROS-MPH & 1.273 & $1.169-1.386$ \\
\hline Atomoxetine & 1.771 & $1.593-1.97$ \\
\hline All combination & Ref & Ref \\
\hline
\end{tabular}

MPR: medication possession ratio, OR: odds ratio, Ref: reference value, CI: confidence interval, IR-MPH: immediate release methylphenidate, ER-MPH: extended release methylphenidate, OROSMPH: osmotic-controlled release oral delivery system methylphenidate

1.6) and pediatrician $(\mathrm{OR}=1.5, \mathrm{CI}=1.2-1.7)$, reference value $=$ others], treatment at a private clinic $(\mathrm{OR}=1.6, \mathrm{CI}=1.5-1.6$, reference $=$ general hospital), and comorbid conditions $(\mathrm{OR}=$ 1.3, $\mathrm{CI}=1.3-1.4$, reference=no comorbidity) were associated 
with medication adherence during continued treatment (Table 4).

\section{DISCUSSION}

Three main findings were identified based on the analyses performed within the framework of the current study. First, the cumulative incidence of index cases that initiated a medication refill for ADHD treatment during the 4 year period was $0.85 \%$, and the mean age of ADHD medication initiation was 10.32 years $(\mathrm{SD}=3.24)$. Second, adherence defined as a MPR of $80 \%$ (dichotomous value) was $66.4 \%$ for boys and $66.8 \%$ for girls, respectively. Third, in the multivariate logistic regression analysis, the medication type, age (10-15 age groups $<16-18$ age groups), clinician specialty, hospital type, and comorbid conditions were associated with medication adherence during continuous treatment assessed via multivariate analysis; sex and insurance type were not associated with adherence.

In our study sample, the cumulative incidence of index cases that initiated a medication refill for ADHD treatment during the 4 year period was $0.85 \%$ (annual rate $0.21 \%$, on average). Compared with the treatment incidences from other countries with a high treatment incidence range from $2.7 \%$ to $3.0 \%$ in the U.S. ${ }^{24,25}$ or a relatively low treatment incidence range from $0.43 \%$ in 2005 and $0.48 \%$ in 2006 in Germany, ${ }^{26}$ the treatment incidence in our study is still low. This finding suggests the possibility that there is an unmet need in ADHD medication usage in Korea. The mean age of the initiation of ADHD medication in the current study was 10.32 years $(\mathrm{SD}=$ 3.24), which was later than other countries. According to a retrospective chart review across Europe, ${ }^{27}$ the age at ADHD diagnosis was 8.9 years $(\mathrm{SD}=2.6)$ [9.1 $(\mathrm{SD}=2.5)$ in France, 8.2 $(\mathrm{SD}=2.1)$ in Germany, $8.7(\mathrm{SD}=2.9)$ in Italy, $8.6(\mathrm{SD}=2.6)$ in the Netherlands, $9.0(\mathrm{SD}=2.3)$ in Spain, and $9.3(\mathrm{SD}=2.8)$ in the UK]. The most common age to initiate medication is between 5 and 9 years in the US based on a nationally representative sample of children ages 5-17 years old from the Medical Expenditure Panel Survey (MEPS) for the years 2000$2002 .{ }^{28}$ Because the children were diagnosed and subsequently treated, their treatment incidence should be less than the previously described countries. These treatment delays appear to be related to the Korean cultural background, which influences delays in the initiation of treatment for other psychiatric illnesses in Korea. ${ }^{29}$ Thus, the earlier identification and intervention of children with ADHD is urgently needed in Korea.

The percentage of patients who exhibited a MPR greater than 80 was approximately $66 \%$ in our study. According to a recent review, ${ }^{1}$ Hodgkins et al. ${ }^{30}$ in the Netherlands reported the MPR 80 in their study as follows: 0.64 for stimulants ( $\mathrm{n}=$ $4,801)$ and 0.67 for non-stimulants $(n=81)$. However, in their study, most children (98\%) initiated treatment with methylphenidate, and $89 \%$ of these children received an immediaterelease formulation. Another retrospective claims-based analysis of a managed care population demonstrated that the MPR 80 was 0.56 for long acting stimulant medication $(n=21,386){ }^{31}$ In the pooled data, Gajria et al. ${ }^{1}$ reported that the MPR 80 in stimulant medication was $0.57(n=26,187)$, non-stimulant medication was $0.67(\mathrm{n}=81)$, long acting medication was 0.56 $(\mathrm{n}=21,805)$, and short acting medication was $0.64(\mathrm{n}=4,382)$ in children and adolescents during a study period of 12 months. In these studies, the patients with non-stimulants were relatively small. Within the 6 months of the study period, according to the pooled data from Sikirica et al..$^{32}$ and Lawson et al., ${ }^{33}$ the MPR 80 in the stimulant group was $0.49(n=14,459)$, the non-stimulant group was $0.61(n=3,087)$, the long acting medication was $0.50(n=13,108)$, and the short acting group was $0.40(n=1,349)$ in children and adolescents. ${ }^{1}$ In our study, we investigated up to 4 years without a time limitation during the study observation period. Therefore, this report is the first study to examine the MPR for more than 2 years. Considering only $8.5 \%$ of the patients in our sample exhibited more than a 30 day gap during the individual follow-up period, the MPR 80 in this study was $0.66-0.67$, which was not different from the previous studies. The adherence estimates were not influenced by the length of the observation periods, e.g., 6 or 12 months; ${ }^{1}$ however, the previous report did not conduct the study for more than 2 years. Our objective was the adherence of the ADHD medication treatment, regardless of medication switching, because in clinical settings, medication switching can occur when the patients grow and a newer medication is introduced, which does not represent non-adherence to treatment; instead, it represents the true treatment adherence with the development of the children.

In our sample, a large proportion of first medication received was OROS-MPH (36.6\%), followed by ER-MPH (34.0\%), IR-MPH (19.7\%) and atomoxetine (6.0\%), as well as multiple combinations $(3.7 \%)$. The adherence rate for the first prescribed medications was significantly different as follows: atomoxetine >ER-MPH, OROS-MPH>IR-MPH. According to Gajria et al., ${ }^{1}$ children and adolescents appeared to exhibit increased adherence to the non-stimulant than stimulant groups. Although atomoxetine was prescribed with severe anxiety disorder or Tourette's syndrome during our study period, the multivariate analysis indicated a significant difference from the other stimulant medications.

Several reports have demonstrated individuals with a younger age at baseline had better adherence to ADHD medication treatments ${ }^{7,16,34,35}$ and older age was a predictor of medication 
discontinuation. ${ }^{13,36}$ For example, a study that used the Canadian RAMQ database reported that the highest adherence rate was identified in the younger than 9-year-old group in patients prescribed stimulants, and more teenagers aged between 15 and 19 years were non adherent to their treatment compared with the other groups. ${ }^{16}$ In Texas Medicaid children with 3-18 years of age, older age (age 13-18) was associated with lower adherence. ${ }^{13}$ In Taiwan, older age was the major predictor of poor adherence to IR MPH in ages 6-17 years and ages 5-16 years. ${ }^{34,35}$ Nevertheless, in our study of 6-18 year old children and adolescents, the 10-15 age group exhibited lower adherence compared with the 16-18 age groups. In South Korea, high school students are under substantial academic pressures, and their parents are concerned regarding their performance. A recent study demonstrated that the pressure on Korean children to study is nearly the highest in the world, especially regarding college or university entry. ${ }^{37}$ This finding may explain why high school students exhibited better adherence compared with middle school students; however, additional studies to support this suggestion are needed in the future.

In our results, patients with comorbid conditions were more likely to adhere compared with each reference variable. Several reports support this result. Among 71 children with ADHD in Toronto, in the absence of teacher-rated oppositional defiant disorder, more teacher-rated ADHD symptoms predicted adherence. ${ }^{7}$ A 36 month follow-up study of 134 children (ages 4-16) demonstrated that the absence of associated disorders, determined by specific protocols, including a semi structured parent interview, was a predictor of medication discontinuation because of functional remission. ${ }^{36}$ Among Texas Medicaid children, comorbid medications were associated with increased adherence. ${ }^{13}$ One explanation is that comorbid conditions lead to the parents' diligence in controlling symptoms. ${ }^{13}$

In our subjects, the participants treated in a private clinic (73.13\%) were 3 times more prevalent compared with the patients treated in a general hospital $(26.87 \%)$. Furthermore, the MPR 80 was doubled for the private clinic users. There may be several reasons for this result. According to a recent report in Korea, ${ }^{38}$ the factors that were associated with the upper-level institutions are males, beneficiaries of Medical Aid, education level, household income, and severe diseases; the last three factors were negatively associated with the level of health status. Thus, we speculated that our results were favorable for the private clinic regarding adherence because of the following factors: there are differences in the utilization patterns for a private clinic compared with a general hospital regarding the availability of the out-patient department clinic schedule for unexpected schedule changes or extra sessions, the type of additional psychosocial programs in the clinic are different, and the severity of the disease is different; however, these factors were not directly assessed in the current study" if the edit maintains the intended meaning. In addition, clinician specialty [psychiatrist $(\mathrm{OR}=1.36,1.12-1.53)$ or pediatrician $(\mathrm{OR}=1.45,1.23-1.71)]$ is positively associated with adherence, which is consistent with a previous report.

Our study has several strengths. First, the use of HIRA data enabled the evaluation of drug use in the entire population of South Korea during a 5-year period. Second, we were able to assess a maximum of 4 consecutive years of data with treatment maintenance regardless of the type of medication used to treat ADHD. Third, it is important that non-stimulant medications, such as atomoxetine, were included in this study, which does not have sufficient data compared with the stimulant medications for analyses using claims data.

There are also several limitations to our study. First, although National health insurance system covers all Korean population, some individuals do not use the national insurance because of personal preference to avoid recode in public data. Second, atomoxetine was introduced in the middle of the study, and there are two main restrictions regarding the prescription indications, which include anxiety conditions and comorbid Tourette syndrome. However, we use comorbid conditions as a cofactor for the multivariate analysis, and the restricted usage can be adjusted using this method. Third, we consider only the starting medication as an index medication; however, there can be medication switching. Thus, the main medication could be different from the starting medication. Fourth, we could not report the fixed persistence rate and the entire duration of the observation because of administrative reasons. Finally, the severity of the disease could not be included in the analyses. ${ }^{14}$

A better understanding of ADHD treatment patterns may lead to initiatives targeted at the improvement of treatment adherence and persistence. When medication types were compared, multiple regression indicated immediate release $\mathrm{MPH}$ and extended-release MPH users were significantly less persistent compared with non-stimulant users. The high school students compared with older elementary and middle school students, treatment by a psychiatrist and pediatrician, at a private clinic, and with comorbid conditions were more likely to adhere compared with each reference variable. Other factors, including severity, family history, costs, type of comorbidities, and switching patterns, will be analyzed in future studies.

\section{Acknowledgments}

This study was supported by a 2013-Grant from the Korean Academy of Medical Sciences. We would like to thank the HIRA for access to the database. 


\section{REFERENCES}

1. Gajria K, Lu M, Sikirica V, Greven P, Zhong Y, Qin P, et al. Adherence, persistence, and medication discontinuation in patients with attentiondeficit/hyperactivity disorder - a systematic literature review. Neuropsychiatr Dis Treat 2014;10:1543-1569.

2. Barkley RA, Fischer M, Smallish L, Fletcher K. Young adult outcome of hyperactive children: adaptive functioning in major life activities. J Am Acad Child Adolesc Psychiatry 2006;45:192-202.

3. Biederman J, Ball SW, Monuteaux MC, Mick E, Spencer TJ, McCreary $\mathrm{M}$, et al. New insights into the comorbidity between ADHD and major depression in adolescent and young adult females. J Am Acad Child Adolesc Psychiatry 2008;47:426-434.

4. Reimer B, Mehler B, D'Ambrosio LA, Fried R. The impact of distractions on young adult drivers with attention deficit hyperactivity disorder (ADHD). Accid Anal Prev 2010;42:842-851.

5. Gupta R, Nower L, Derevensky JL, Blaszczynski A, Faregh N, Temcheff C. Problem gambling in adolescents: an examination of the pathways model. J Gambl Stud 2013; 29:575-588.

6. Biederman J, Ball SW, Monuteaux MC, Surman CB, Johnson JL, Zeitlin S. Are girls with $\mathrm{ADHD}$ at risk for eating disorders? Results from a controlled, five-year prospective study. J Dev Behav Pediatr 2007;28:302307.

7. Thiruchelvam D, Charach A, Schachar RJ. Moderators and mediators of long-term adherence to stimulant treatment in children with ADHD. J Am Acad Child Adolesc Psychiatry 2001;40:922-928.

8. Barbaresi WJ, Katusic SK, Colligan RC, Weaver AL, Jacobsen SJ. Modifiers of long-term school outcomes for children with attention-deficit/ hyperactivity disorder: does treatment with stimulant medication make a difference? Results from a population-based study. J Dev Behav Pediatr 2007;28:274-287.

9. Wilens TE, Adamson J, Monuteaux MC, Faraone SV, Schillinger M, Westerberg D, et al. Effect of prior stimulant treatment for attentiondeficit/hyperactivity disorder on subsequent risk for cigarette smoking and alcohol and drug use disorders in adolescents. Arch Pediatr Adolesc Med 2008;162:916-921.

10. Biederman J, Monuteaux MC, Spencer T, Wilens TE, Faraone SV. Do stimulants protect against psychiatric disorders in youth with $\mathrm{ADHD}$ ? A 10-year follow-up study. Pediatrics 2009;124:71-78.

11. Charach A, Gajaria A. Improving psychostimulant adherence in children with ADHD. Expert Rev Neurother 2008;8:1563-1571.

12. Murray DW, Arnold LE, Swanson J, Wells K, Burns K, Jensen P, et al. A clinical review of outcomes of the multimodal treatment study of children with attention-deficit/hyperactivity disorder (MTA). Curr Psychiatry Rep 2008;10:424-431.

13. Barner JC, Khoza S, Oladapo A. ADHD medication use, adherence, persistence and cost among Texas Medicaid children. Curr Med Res Opin 2011;27(Suppl 2):13-22.

14. Charach A, Fernandez R. Enhancing ADHD medication adherence: challenges and opportunities. Curr Psychiatry Rep 2013;15:371.

15. Perwien A, Hall J, Swensen A, Swindle R. Stimulant treatment patterns and compliance in children and adults with newly treated attention-deficit/hyperactivity disorder. J Manag Care Pharm 2004;10:122-129.

16. Lachaine J, Beauchemin C, Sasane R, Hodgkins PS. Treatment patterns, adherence, and persistence in ADHD: a Canadian perspective. Postgrad Med 2012;124:139-148.

17. McCarthy S, Wilton L, Murray ML, Hodgkins P, Asherson P, Wong IC. Persistence of pharmacological treatment into adulthood, in UK primary care, for ADHD patients who started treatment in childhood or adolescence. BMC Psychiatry 2012;12:219.

18. Pottegard A, Bjerregaard BK, Glintborg D, Hallas J, Moreno SI. The use of medication against attention deficit hyperactivity disorder in Denmark: a drug use study from a national perspective. Eur J Clin Pharmacol 2012;68:1443-1450.
19. Pottegard A, Bjerregaard BK, Glintborg D, Kortegaard LS, Hallas J, Moreno SI. The use of medication against attention deficit/hyperactivity disorder in Denmark: a drug use study from a patient perspective. Eur J Clin Pharmacol 2013;69:589-598.

20. Kim JS. The Operation of Nationwide Health Insurance and its Implications. Seoul: Korea Development Institute (KDI) School of Public Policy and Management; 2012.

21. National Helath Insurance Service. National Health Insurance Statistical Yearbook 2014. Seoul: National Health Insurance Service; 2014.

22. National Health Insurance Service. National Health Insurance Statistical Yearbook 2011. Seoul: National Health Insurance Service; 2011.

23. Hong M, Kwack YS, Joung YS, Lee SI, Kim B, Sohn SH, et al. Nationwide rate of attention-deficit hyperactivity disorder diagnosis and pharmacotherapy in Korea in 2008-2011. Asia Pac Psychiatry 2014;6:379-385.

24. Polanczyk G, de Lima MS, Horta BL, Biederman J, Rohde LA. The worldwide prevalence of ADHD: a systematic review and metaregression analysis. Am J Psychiatry 2007;164:942-948.

25. Zuvekas SH, Vitiello B, Norquist GS. Recent trends in stimulant medication use among U.S. children. Am J Psychiatry 2006;163:579-585.

26. Kraut AA, Langner I, Lindemann C, Banaschewski T, Petermann U, Petermann F, et al. Comorbidities in ADHD children treated with methylphenidate: a database study. BMC Psychiatry 2013;13:11.

27. Hodgkins P, Setyawan J, Mitra D, Davis K, Quintero J, Fridman M, et al. Management of ADHD in children across Europe: patient demographics, physician characteristics and treatment patterns. Eur J Pediatr 2013;172:895-906.

28. Hudson JL, Miller GE, Kirby JB. Explaining racial and ethnic differences in children's use of stimulant medications. Med Care 2007;45:1068-1075.

29. Ki M, Paik JW, Choi KS, Ryu SH, Han C, Lee K, et al. Delays in depression treatment among Korean population. Asia Pac Psychiatry 2014; 6:414-424.

30. Hodgkins P, Sasane R, Meijer WM. Pharmacologic treatment of attention-deficit/hyperactivity disorder in children: incidence, prevalence, and treatment patterns in the Netherlands. Clin Ther 2011;33:188-203.

31. Christensen L, Sasane R, Hodgkins P, Harley C, Tetali S. Pharmacological treatment patterns among patients with attention-deficit/hyperactivity disorder: retrospective claims-based analysis of a managed care population. Curr Med Res Opin 2010;26:977-989.

32. Sikirica V, Xie J, He TL, Erde MH, Hodgkins P, Yang H, et al. Immediate-release versus extended-release guanfacine for treatment of attention-deficit/hyperactivity disorder. Am J Pharm Benefits 2013;5:e85-e94.

33. Lawson KA, Johnsrud M, Hodgkins P, Sasane R, Crismon ML. Utilization patterns of stimulants in ADHD in the Medicaid population: a retrospective analysis of data from the Texas Medicaid program. Clin Ther 2012;34:944-956. e4.

34. Gau SS, Shen HY, Chou MC, Tang CS, Chiu YN, Gau CS. Determinants of adherence to methylphenidate and the impact of poor adherence on maternal and family measures. J Child Adolesc Psychopharmacol 2006; 16:286-297.

35. Gau SS, Chen SJ, Chou WJ, Cheng H, Tang CS, Chang HL, et al. National survey of adherence, efficacy, and side effects of methylphenidate in children with attention-deficit/hyperactivity disorder in Taiwan. J Clin Psychiatry 2008;69:131-140.

36. Atzori P, Usala T, Carucci S, Danjou F, Zuddas A. Predictive factors for persistent use and compliance of immediate-release methylphenidate: a 36-month naturalistic study. J Child Adolesc Psychopharmacol 2009; 19:673-681.

37. Pressure to study on children here greater than anywhere else. Available at: http://www.koreatimes.co.kr/www/news/nation/2015/03/116_175007. html. Accessed March 11, 2015.

38. You CH, Kwon YD. Factors influencing medical institution selection for outpatient services. J Korean Med Assoc 2012;55:898-910. 